

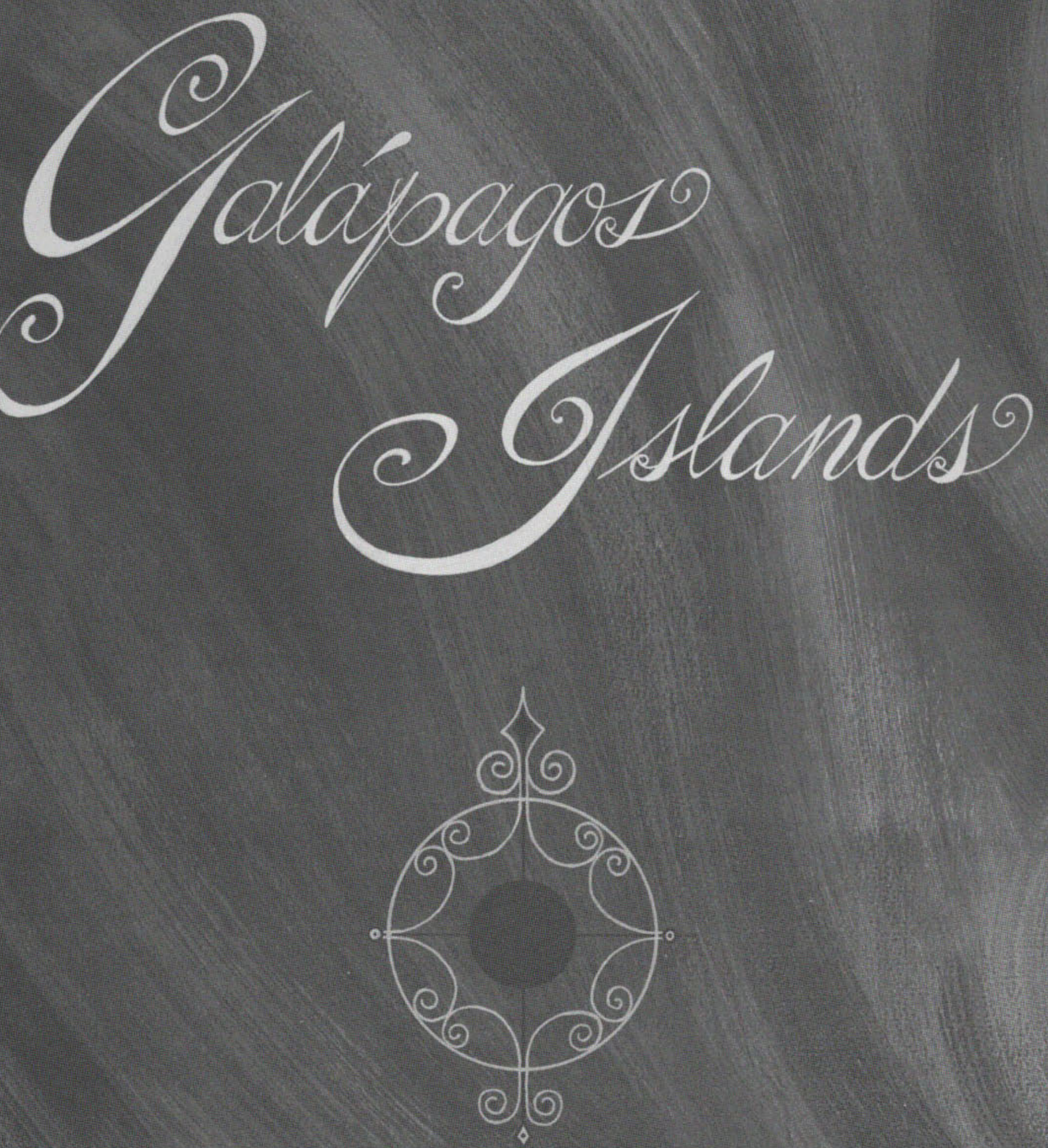


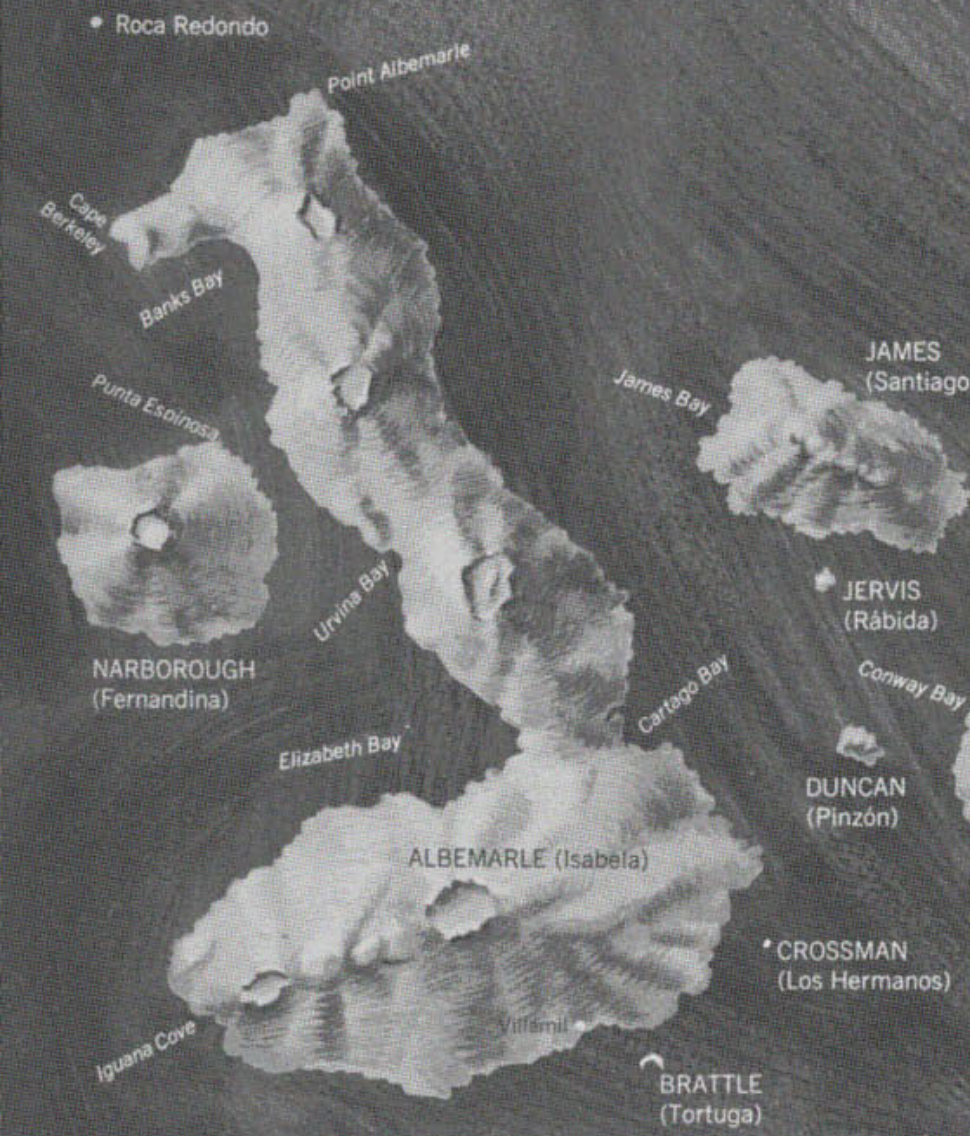

BINDLOE
(Marchena)

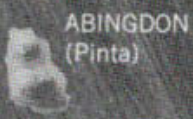

(Bartholome)

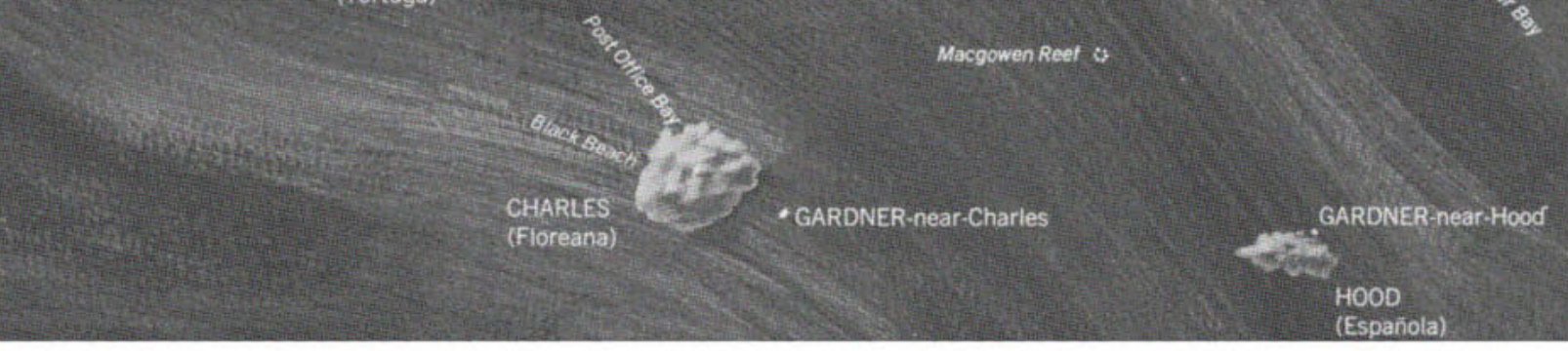

N. SEYMOUR

S. SEYMOUR

is (Baltra)

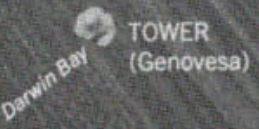

(7)

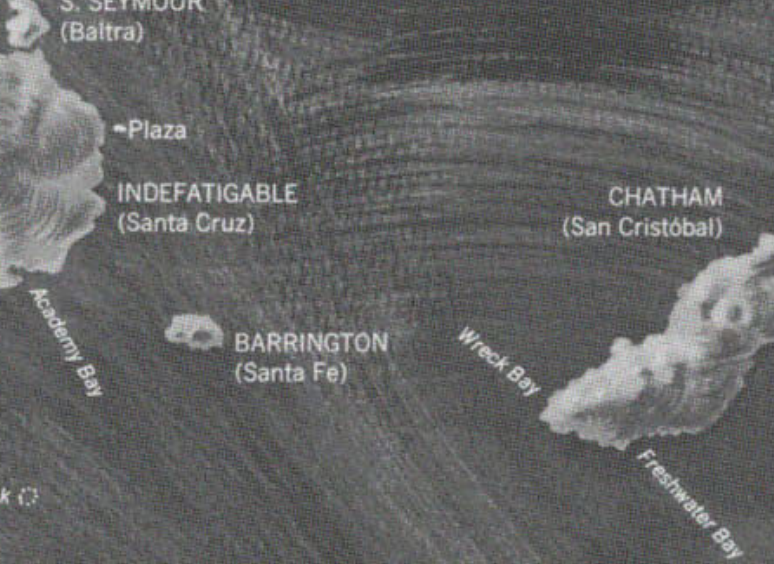

INDEFATIGABLE
(Santa Cruz)
(San Cristobal)

(Española) 



\section{THE GaLÁPAgOS}

Proceedings of the Symposia of the Galápagos International Scientific Project 



\section{THE GALÁPAGOS}

Proceedings of the Symposia of the

Galápagos International Scientific Project

Edited by RORERT I. BOWMAN

UNIVERSITY OF CALIFORNIA PRESS

Berkeley and Los Angeles 1966 
UNIVERSITY OF CALIFORNIA PHESS BERKELEY AND LOS ANGELES, CALIFORNIA

CAMHRIDGE UNIVERSITY PRESS LONDON, ENCLAND

(1) 1966 HY THE RECENTS OF THE UNIVERSITY OF CALIFORNIA

LIBRAHY OF CONGHESS CATALOC CARD NUMHER: $66: 14109$

FINANCIAL SUPPORT WAS PROVIDED BY 'THE NATIONAL SCIENCE FOUNDATION

DESIGNED BY RICHARD CORK

MANUFACTURED IN THE UNITED STATES OF AMIERICA 